\title{
Effects of Diet and Exercise on Endocrine Function of Skeletal Muscle ${ }^{\dagger}$
}

\author{
Jedrzej Antosiewicz 1,* , Andzelika Borkowska 1, Malagorzata Halon-Golabek ${ }^{1}$, Jakub Kortas ${ }^{2}$, \\ Ewa Ziemann ${ }^{2}$ and Anna Herman-Antosiewicz ${ }^{3}$ \\ 1 Department of Bioenergetics and Physiology of Exercise, Medical University of Gdansk, Debinki 1, \\ 80-211 Gdansk, Poland; jant@gumed.edu.pl (A.B.); andzelika.b@gumed.edu.pl or \\ m.halon@gumed.edu.pl(M.H.-G.) \\ 2 Department of Physiology and Pharmacology, Gdansk University of Physical Education and Sport, \\ Kazimierza Gorskiego 1, 80-336 Gdansk, Poland; jakubantonikortas@gmail.com (J.K.); \\ ziemann.ewa@gmail.com (E.Z.) \\ 3 Department of Medical Biology and Genetics, University of Gdansk, Wita Stwosza 59, \\ 80-308 Gdansk, Poland; anna.herman@biol.ug.edu.pl \\ * Correspondence: jedrzej.antosiewicz@gumed.edu.pl \\ + Presented at the Meeting of the NutRedOx COST Action CA16112 "Natural Products and the Hallmarks of \\ Chronic Diseases", Luxemburg, 25-27 March 2019.
}

Published: 6 May 2019

Keywords: myokines; IL-10; inflammation; antioxidants; iron

Skeletal muscle has been recognized as an endocrine tissue that releases appreciable amounts of circulating proteins, called myokines. Currently, we know that the skeletal muscles synthesize several hundreds of peptides classified as myokines, and muscle contraction stimulates their release $[1,2]$. Myokines can act in autocrine, paracrine or endocrine mode and there is an increasing number of data showing that they can affect different organs and tissues, e.g., the brain, bones, adipocyte tissue, heart artery, and many others [3]. For instance, the interleukins IL- 6 and IL-10, released by the muscles during exercise, exert powerful local and systemic anti-inflammatory effects. Furthermore, IL-10 has been shown to provide cardio-and neuroprotection, which is mediated by the activation of anti-apoptotic protein kinase B (PKB or Akt) [4,5]. In addition, myokines like SPARC and oncostatin $\mathrm{M}$ show inhibitory activity against colon and breast cancer cells, respectively. Skeletal muscles represent the largest organ of the human body (the muscles constitute approximately $40 \%$ of total body mass), thus their role in the regulation of metabolic processes via myokines appears to be very important. Unfortunately, there is a limited amount of data demonstrating the effects of nutraceuticals on exercise-induced release of myokines. It has been shown that release of IL-6 from skeletal muscle was inhibited in persons supplemented with vitamin $C$ and E. We hypothesize that natural compounds may exert their protective activity against some human diseases by modulating myokine synthesis.

Funding: This work is based upon work from COST Action NutRedOx-CA16112 supported by COST (European Cooperation in Science and Technology).

Conflicts of Interest: The authors declare no conflict of interest.

\section{References}

1. Henningsen, J.; Rigbolt, K.T.; Blagoev, B.; Pedersen, B.K.; Kratchmarova, I. Dynamics of the skeletal muscle secretome during myoblast differentiation. Mol. Cell. Proteom. 2010, 9, 2482-2496, doi:10.1074/mcp.M110.002113. 
2. Huh, J.Y. The role of exercise-induced myokines in regulating metabolism. Arch. Pharmacal. Res. 2018, 41, 14-29, doi:10.1007/s12272-017-0994-y.

3. Giudice, J.; Taylor, J.M. Muscle as a paracrine and endocrine organ. Curr. Opin. Pharmacol. 2017, 34, 49-55, doi:10.1016/j.coph.2017.05.005.

4. Sharma, S.; Yang, B.; Xi, X.; Grotta, J.C.; Aronowski, J.; Savitz, S.I. IL-10 directly protects cortical neurons by activating PI-3 kinase and STAT-3 pathways. Brain Res. 2011, 1373, 189-194, doi:10.1016/j.brainres.2010.11.096.

5. Cai, Z.; Luo, W.; Zhan, H.; Semenza, G.L. Hypoxia-inducible factor 1 is required for remote ischemic preconditioning of the heart. Proc. Natl. Acad. Sci. USA 2013, 110, 17462-17467. doi:10.1073/pnas.1317158110.

(C) 2019 by the authors. Licensee MDPI, Basel, Switzerland. This article is an open access article distributed under the terms and conditions of the Creative Commons Attribution (CC BY) license (http://creativecommons.org/licenses/by/4.0/). 